\title{
Shape sensitivity analysis of composites in contact using the boundary element method
}

DOI:

10.1016/j.enganabound.2008.04.008

\section{Document Version}

Accepted author manuscript

Link to publication record in Manchester Research Explorer

\section{Citation for published version (APA):}

Tafreshi, A. (2009). Shape sensitivity analysis of composites in contact using the boundary element method.

Engineering Analysis with Boundary Elements, 33(2), 215-224. https://doi.org/10.1016/j.enganabound.2008.04.008

\section{Published in:}

Engineering Analysis with Boundary Elements

\section{Citing this paper}

Please note that where the full-text provided on Manchester Research Explorer is the Author Accepted Manuscript or Proof version this may differ from the final Published version. If citing, it is advised that you check and use the publisher's definitive version.

\section{General rights}

Copyright and moral rights for the publications made accessible in the Research Explorer are retained by the authors and/or other copyright owners and it is a condition of accessing publications that users recognise and abide by the legal requirements associated with these rights.

\section{Takedown policy}

If you believe that this document breaches copyright please refer to the University of Manchester's Takedown Procedures [http://man.ac.uk/04Y6Bo] or contact uml.scholarlycommunications@manchester.ac.uk providing relevant details, so we can investigate your claim.

\section{OPEN ACCESS}




\title{
SHAPE SENSITIVITY ANALYSIS OF COMPOSITES IN CONTACT USING THE BOUNDARY ELEMENT METHOD
}

\author{
Azam Tafreshi School of Mechanical, Aerospace and Civil Engineering, MACE \\ The University of Manchester, P.O.Box 88, Sackville Street \\ Manchester M60 1QD \\ azam.tafreshi@manchester.ac.uk
}

\begin{abstract}
This paper presents the application of the boundary element method to the shape sensitivity analysis of two-dimensional composite structures in contact. A directly differentiated form of boundary integral equation with respect to geometric design variables is used to calculate shape design sensitivities for anisotropic materials with frictionless contact. The selected design variables are the coordinates of the boundary points either in the contact or non-contact area. Three example problems with anisotropic material properties are presented to validate the applications of this formulation.
\end{abstract}

Keywords: Sensitivity analysis, contact analysis, shape optimisation, boundary element method, composites, anisotropic materials

\section{Introduction}

Shape sensitivity analysis, that is the calculation of quantitative information on how the response of a structure is affected by changes in the variables that define its shape, is a fundamental requirement for shape optimization. Shape optimization is an important area of current development in mechanical and structural design. Computerized procedures using optimization algorithms can iteratively determine the optimum shape of a component while satisfying some objectives, without at the same time violating the design constraints. The boundary element method being a surfaceoriented technique is well suited for shape optimization problems [1-5]. 
In the last two decades important advancements have been made in the analysis of contact problems using the finite element or boundary element methods. The latter seems to have proved advantageous in treating the contact between linear elastic solids [6-8]. The contact surface design is usually the first requirement to reduce the stress peaks. Therefore, various efforts have been made to produce optimal designs which increase the performance and reliability of the structure in contact environments [9-13]. The effect of material properties should next be considered in conjunction with the shape optimization to obtain the required performance of the component. However, in this field of research the analysis has been mostly concentrated on isotropic materials.

The application of composites in aerospace, automobile, civil and marine industries is well established today due to the known benefits such as high specific stiffness or strength and the material's tailoring facilities for creating high performance structures. An understanding of the interactions between the composite material components and their optimum contact surface design can further enhance their potential applications.

The objective of this work is directed towards the shape sensitivity analysis of twodimensional anisotropic structures in frictionless contact. This study continues the previous works of the author on the shape optimization of anisotropic structures using the boundary element method [1-3], where the effect of material properties on the optimum shape design of structures was investigated.

In Ref. [3], a directly differentiated form of the BIE, with respect to boundary point coordinates, was used to calculate stress and displacement derivatives for two- 
dimensional anisotropic structures. In Ref. [2], the optimal shape design of an anisotropic elastic body of maximum stiffness and minimum weight under specified loadings and using the boundary element method, was obtained. The elastic compliance of the structure was minimized while there were constraints on the maximum stress and weight of the structure. The objective of the work in Ref. [1] was directed towards the optimal positioning of features in anisotropic structures for maximum stiffness while the weight remains unchanged. The elastic compliance was minimized while there were constraints on the maximum stress and the geometry of the structure. To the author's knowledge, no other publications are available on the shape optimization of composite materials using the boundary elements.

Here, the design sensitivity analysis of composite structures in contact has been carried out by direct differentiation of the structural response rather than using the finite difference method. The design variables are taken as the coordinates of some nodes on the boundaries of either body which is in contact. The selection of the boundary points as the design variables is more general than selecting simple geometrical variables such as radii, etc. The advantage of the proposed method is that it can be applied to any geometry, not necessarily regular shapes. However, when entire segments of the boundary or domain are governed by a single variable such as radius, the relevant velocity terms are applied together in the sensitivity analysis with respect to that variable [1]. The formulation obtained in the present study may be employed in conjunction with any numerical optimization algorithm for the shape optimization of anisotropic components in contact. 


\section{Constitutive equations for plane anisotropic elasticity}

The stress-strain relations for a two-dimensional homogeneous, anisotropic elastic body in plane stress is

$$
\left[\begin{array}{c}
\varepsilon_{11} \\
\varepsilon_{22} \\
2 \varepsilon_{12}
\end{array}\right]=\left[\begin{array}{lll}
a_{11} & a_{12} & a_{16} \\
a_{12} & a_{22} & a_{26} \\
a_{16} & a_{26} & a_{66}
\end{array}\right]\left[\begin{array}{c}
\sigma_{11} \\
\sigma_{22} \\
\sigma_{12}
\end{array}\right]
$$

where $\sigma_{j k}$ and $\varepsilon_{j k}(\mathrm{j}, \mathrm{k}=1,2)$ are the stresses and strains, respectively [14]. The coefficients $\mathrm{a}_{\mathrm{mn}}$ are the elastic compliances of the material. These compliances can be written in terms of engineering constants as

$$
\begin{aligned}
& a_{11}=\frac{1}{E_{1}} \quad, \quad a_{22}=\frac{1}{E_{2}} \quad, \quad a_{12}=-\frac{v_{12}}{E_{1}}=-\frac{v_{21}}{E_{2}} \\
& a_{66}=\frac{1}{G_{12}} \quad, \quad a_{16}=\frac{\eta_{12,1}}{E_{1}}=\frac{\eta_{1,12}}{G_{12}} \quad, \quad a_{26}=\frac{\eta_{12,2}}{E_{2}}=\frac{\eta_{2,12}}{G_{12}}
\end{aligned}
$$

where $E_{k}$ is Young's modulus in the $x_{k}$ direction, $G_{12}$ is the shear modulus in the $x_{1}-x_{2}$ plane and $v_{\mathrm{jk}}$ is Poisson's ratio. The quantities $\eta_{j k, 1}$ and $\eta_{1, j k}$ are referred to by Lehknitskii [15] as the coefficients of mutual influence of the first and second kind, respectively. For the plane strain case, equation (1) remains applicable, provided that $a_{j k}$ is replaced by $b_{j k}$.

$$
\begin{aligned}
& b_{j k}=a_{j k}-\frac{a_{j 3} a_{k 3}}{a_{33}} \quad ; \quad j, k=1,2,6 \\
& a_{j 3}=-\frac{v_{j 3}}{E_{j}}, a_{33}=\frac{1}{E_{3}}, a_{63}=\frac{\eta_{12,3}}{E_{3}}=\frac{\eta_{3,12}}{G_{12}}
\end{aligned}
$$

where the index 3 refers to the $\mathrm{x}_{3}$ direction. For especially orthotropic materials, $\mathrm{a}_{16}=\mathrm{a}_{26}=\mathrm{a}_{63}=0 .[15]$. 
The compatibility equation of strains is

$\frac{\partial^{2} \varepsilon_{11}}{\partial x_{2}^{2}}+\frac{\partial^{2} \varepsilon_{22}}{\partial x_{1}^{2}}=2 \frac{\partial^{2} \varepsilon_{12}}{\partial x_{1} \partial x_{2}}$

and equilibrium is satisfied by taking stresses in terms of derivatives of the Airy stress function $\phi\left(\mathrm{x}_{1}, \mathrm{x}_{2}\right)$ as

$$
\sigma_{11}=\frac{\partial^{2} \phi}{\partial x_{2}^{2}}, \sigma_{22}=\frac{\partial^{2} \phi}{\partial x_{1}^{2}}, \sigma_{12}=-\frac{\partial^{2} \phi}{\partial x_{1} \partial x_{2}}
$$

Combining equations (1), (4) and (5), the governing equation for the two-dimensional problem of anisotropic elasticity can be obtained as

$$
a_{22} \frac{\partial^{4} \phi}{\partial x_{1}^{4}}-2 a_{26} \frac{\partial^{4} \phi}{\partial x_{1}^{3} \partial x_{2}}+\left(2 a_{12}+a_{66}\right) \frac{\partial^{4} \phi}{\partial x_{1}^{2} \partial x_{2}^{2}}-2 a_{16} \frac{\partial^{4} \phi}{\partial x_{1} \partial x_{2}^{3}}+a_{66} \frac{\partial^{4} \phi}{\partial x_{2}^{4}}=0 .
$$

By introducing the operator $\mathrm{D}_{\mathrm{s}}(\mathrm{s}=1,4)$ as

$D_{s}=\frac{\partial}{\partial x_{2}}-\mu_{s} \frac{\partial}{\partial x_{1}}$

Equation (6) becomes

$D_{1} D_{2} D_{3} D_{4}(\phi)=0$.

and $\mu_{\mathrm{s}}$ are the four roots of the characteristic equation

$$
\left[a_{22}-2 \mu a_{26}+\left(2 a_{12}+a_{66}\right) \mu^{2}-2 a_{16} \mu^{3}+a_{11} \mu^{4}\right] \frac{d^{4} \phi}{d z^{4}}=0 .
$$

To have a solution for the stress function, the term in square brackets must be zero. Lehknitskii [15] has shown that, for an anisotropic material, these roots are distinct and must be purely imaginary or complex and they may be denoted by $\mu_{1}=\alpha_{1}+i \beta_{1} \quad, \quad \mu_{1}=\alpha_{2}+i \beta_{2} \quad, \quad \mu_{3}=\bar{\mu}_{1} \quad, \quad \mu_{4}=\bar{\mu}_{2}$

where $\alpha_{\mathrm{j}}$ and $\beta_{\mathrm{j}}(\mathrm{j}=1,2)$ are real constants, $i=\sqrt{-1}$ and the overbar represents the complex conjugate. Therefore, the stresses and displacements in an anisotropic body can be expressed in terms of the complex coordinates $\left(\mathrm{z}_{\mathrm{j}}\right)$ 
$z_{j}=x_{1}+\mu_{j} x_{2} \quad j=1,2$

and their complex conjugates.

\section{Review of the boundary element method for anisotropic materials in contact}

The analytical formulation of the direct boundary integral equation (BIE) for plane anisotropic elasticity may be developed by following the same steps as in the isotropic case [16-18].

The boundary element method is based on the unit load solutions in an infinite body, known as the fundamental solutions, used with the reciprocal work theorem and appropriate limit operations. The boundary integral equation (BIE) of the BEM for anisotropic materials is an integral constraint equation relating boundary tractions $\left(\mathrm{t}_{\mathrm{j}}\right)$ and boundary displacements $\left(\mathrm{u}_{\mathrm{j}}\right)$ and it may be written as

$C_{j k} u_{j}(P)+\int_{s} T_{j k}(P, Q) u_{j}(Q) d s(Q)=\int_{s} U_{j k}(P, Q) t_{j}(Q) d s(Q) \quad j, k=1,2$

$\mathrm{P}\left(\zeta_{1}, \zeta_{2}\right)$ and $\mathrm{Q}\left(\mathrm{x}_{1}, \mathrm{x}_{2}\right)$ are the load and field points, respectively. $\mathrm{U}_{\mathrm{jk}}(\mathrm{P}, \mathrm{Q})$ and $\mathrm{T}_{\mathrm{jk}}(\mathrm{P}, \mathrm{Q})$ are the fundamental solutions that represent the displacements and tractions, respectively, in the $\mathrm{x}_{\mathrm{k}}$ direction at $\mathrm{Q}$ because of a unit load in the $\mathrm{x}_{\mathrm{j}}$ direction at $\mathrm{P}$ in an infinite body. The constant $\mathrm{C}_{\mathrm{jk}}$ depends on the local geometry of the boundary at $\mathrm{P}$, whether it lies on a smooth surface or a sharp corner. In terms of the generalized complex variables

$$
\begin{aligned}
& z_{1}=\left(x_{1}-\zeta_{1}\right)+\mu_{1}\left(x_{2}-\zeta_{2}\right) \\
& z_{2}=\left(x_{1}-\zeta_{1}\right)+\mu_{2}\left(x_{2}-\zeta_{2}\right)
\end{aligned}
$$

the fundamental solutions for displacements and tractions, respectively, can be written 


$$
\begin{aligned}
& U_{j k}=2 \operatorname{Re}\left[r_{k 1} A_{j 1} \ln \left(z_{1}\right)+r_{k 2} A_{j 2} \ln \left(z_{2}\right)\right\rfloor \\
& T_{j 1}=2 n_{1} \operatorname{Re}\left[\mu_{1}^{2} A_{j 1} / z_{1}+\mu_{2}^{2} A_{j 2} / z_{2}\right]-2 n_{2} \operatorname{Re}\left[\mu_{1} A_{j 1} / z_{1}+\mu_{2} A_{j 2} / z_{2}\right] \\
& T_{j 2}=-2 n_{1} \operatorname{Re}\left[\mu_{1} A_{j 1} / z_{1}+\mu_{2} A_{j 2} / z_{2}\right]+2 n_{2} \operatorname{Re}\left[A_{j 1} / z_{1}+A_{j 2} / z_{2}\right]
\end{aligned}
$$

where $n_{j}$ are the unit outward normal components at $Q$ with respect to the $x_{1}-x_{2}$ coordinate system. The constants $\mathrm{r}_{\mathrm{kj}}$ are

$$
\begin{aligned}
& r_{1 j}=a_{11} \mu_{j}^{2}+a_{12}-a_{16} \mu_{j} \\
& r_{2 j}=a_{12} \mu_{j}+a_{22} / \mu_{j}-a_{26}
\end{aligned}
$$

and $\mathrm{A}_{\mathrm{jk}}$ are complex constants that can be obtained from the following set of equations:

$$
\begin{aligned}
& A_{j 1}-\bar{A}_{j 1}+A_{j 2}-\bar{A}_{j 2}=\delta_{j 2} / 2 \pi i \\
& \mu_{1} A_{j 1}-\bar{\mu}_{1} \bar{A}_{j 1}+\mu_{2} A_{j 2}-\bar{\mu}_{2} \bar{A}_{j 2}=-\delta_{j 1} / 2 \pi i \\
& r_{11} A_{j 1}-\bar{r}_{11} \bar{A}_{j 1}+r_{21} A_{j 2}-\bar{r}_{21} \bar{A}_{j 2}=0 . \\
& r_{12} A_{j 1}-\bar{r}_{12} \bar{A}_{j 1}+r_{22} A_{j 2}-\bar{r}_{22} \bar{A}_{j 2}=0 .
\end{aligned}
$$

when two bodies are in contact, equation 12 is employed individually for each body involved. In general, the equations can be written as

$$
C_{j k}^{(L)} u_{j}^{(L)}(P)+\int_{s(L)} T_{j k}^{(L)}(P, Q) u_{j}^{(L)}(Q) d s^{(L)}(Q)=\int_{s} U_{j k}^{(L)}(P, Q) t_{j}^{(L)}(Q) d s^{(L)}(Q) \quad j, k=1,2
$$

where $\mathrm{L}(\mathrm{A}, \mathrm{B})$ represents the bodies in contact. See Fig. 1. The potential contact boundary is denoted as $S_{C}^{L}$ and the non-contact boundary as $S_{N C}^{L}$, as Fig. 1 illustrates. These equations are coupled together via the relations between the displacements and tractions in the contact areas.

The boundary-element implementation of equation (17) entails boundary discretization. Quadratic isoparametric elements can be employed for the analyses. Substitution of these isoparametric representations into equation (17) will result in a 
set of linear algebraic equations for the unknown displacements and tractions at the nodes on the boundary of the solution domain as follows:

$A U=B$

where $\mathrm{A}$ is the final coefficient matrix, $\mathrm{U}$ is a vector containing the unknown displacements or tractions. The second member B is a vector which consists of all the known values multiplied by corresponding matrix elements. However, for the nodes in the contact area, neither the displacements nor the tractions are known. Depending on the contact conditions, there are certain relationships between the displacements and tractions of node pairs. Inside the contact zone the discretization is made in such a way that both bodies contain the same number of elements and nodes. Furthermore, the elements from each surface of the interface must have the same geometries and dimensions in the un-deformed state.

In the case of stick contact node pair $(a, b)$ where there is no relative slip $u_{i}^{a}+x_{i}^{a}=u_{i}^{b}+x_{i}^{b} \quad, \quad t_{i}^{a}+t_{i}^{b}=0 . \quad i=1,2$

For the frictionless node pairs, all the relations which hold between the nodal tractions and displacements for the Coulomb slip contact condition are applied, except that the value of 'Coulomb coefficient of friction' is set to zero [6, 7].

For the frictionless contact, it is assumed that the slip is in the local tangential direction. If $\left(\Delta \mathrm{u}_{\mathrm{s}}\right)$ is the amount of slip between node pair a and $\mathrm{b}$ in the tangential direction, then the following displacement relations can be written in the local coordinates,

$u_{t}^{a}=u_{t}^{b}+\Delta u_{s} \quad, \quad u_{n}^{a}=u_{n}^{b}$ 
where $\mathrm{u}_{\mathrm{t}}$ and $\mathrm{u}_{\mathrm{n}}$ are the components of the displacement in the tangential and normal directions, respectively. If these relations are translated into global coordinates, then

$$
\begin{aligned}
& u_{x}^{a}+x^{a}=u_{x}^{b}+x^{b}+\Delta u_{s} \cos \theta_{c} \\
& u_{y}^{a}+y^{a}=u_{y}^{b}+y^{b}+\Delta u_{s} \sin \theta_{c}
\end{aligned}
$$

where $\theta_{\mathrm{c}}$ is the contact angle. From equations (21) the amount of slip $\left(\Delta \mathrm{u}_{\mathrm{s}}\right)$ can be obtained:

$$
\Delta u_{s}=\left(u_{x}^{a}-u_{x}^{b}+x^{a}-x^{b}\right) / \cos \theta_{c}
$$

and therefore using equations (21) and (22) $u_{y}^{b}$ can be written in terms of $u_{x}^{a}, u_{x}^{b}, u_{y}^{a}$ as follows:

$$
u_{y}^{b}=u_{y}^{a}+\left(y^{a}-y^{b}\right)+\left(u_{x}^{b}-u_{x}^{a}+x^{b}-x^{a}\right) \tan \theta_{c}
$$

Here only the frictionless contact is considered. For the application of the contact conditions and construction of the final system of equations refer to Ref. [19].

\section{Direct differentiation of the boundary integral equation}

Direct differentiation of the boundary integral equation with respect to a design variable, $x_{h}(h=1,2)$ (which is most likely to be the coordinate of a node on the movable part of the boundary) results in the following equation:

$$
\begin{aligned}
& C_{j k}^{(L)} \frac{\partial u_{j}^{(L)}(P)}{\partial x_{h}}+\frac{\partial C_{j k}^{(L)}}{\partial x_{h}} u_{j}^{(L)}(P)+\int_{s(L)}\left[\frac{\partial T_{j k}^{(L)}(P, Q)}{\partial x_{h}} u_{j}^{(L)}(Q)+T_{j k}^{(L)}(P, Q) \frac{\partial u_{j}^{(L)}(Q)}{\partial x_{h}}\right] d s^{(L)}(Q)+ \\
& \int_{s(L)}\left[T_{j k}^{(L)}(P, Q) u_{j}^{(L)}(Q)\right] \frac{\partial\left[d s^{(L)}(Q)\right]}{\partial x_{h}}=\int_{s(L)}\left[\frac{\partial U_{j k}^{(L)}(P, Q)}{\partial x_{h}} t_{j}^{(L)}(Q)+U_{j k}^{(L)}(P, Q) \frac{\partial t_{j}^{(L)}(Q)}{\partial x_{h}}\right] d s^{(L)}(Q) \\
& \int_{s} U_{j k}^{(L)}(P, Q) t_{j}^{(L)}(Q) \quad \frac{\partial\left[d s^{(L)}(Q)\right]}{\partial x_{h}} \quad j, k=1,2
\end{aligned}
$$


The derivatives of the terms that only depend on the geometry will be carried out similar to the isotropic materials $[4,5]$. The derivatives of the kernels for anisotropic materials will be as follows [3]:

$$
\begin{aligned}
\frac{\partial U_{j k}}{\partial x_{h}} & =2 \frac{\partial}{\partial x_{h}}\left[\operatorname{Re}\left(r_{k 1} A_{j 1} \ln \left(z_{1}\right)+r_{k 2} A_{j 2} \ln \left(z_{2}\right)\right)\right] \\
\frac{\partial T_{j 1}}{\partial x_{h}} & =2 n_{1} \frac{\partial}{\partial x_{h}}\left[\operatorname{Re}\left(\frac{\mu_{1}^{2} A_{j 1}}{z_{1}}+\frac{\mu_{2}^{2} A_{j 2}}{z_{2}}\right)\right]+2 \operatorname{Re}\left(\frac{\mu_{1}^{2} A_{j 1}}{z_{1}}+\frac{\mu_{2}^{2} A_{j 2}}{z_{2}}\right) \frac{\partial\left(n_{1}\right)}{\partial x_{h}} \\
& -2 n_{2} \frac{\partial}{\partial x_{h}}\left[\operatorname{Re}\left(\frac{\mu_{1} A_{j 1}}{z_{1}}+\frac{\mu_{2} A_{j 2}}{z_{2}}\right)\right]-2 \operatorname{Re}\left(\frac{\mu_{1} A_{j 1}}{z_{1}}+\frac{\mu_{2} A_{j 2}}{z_{2}}\right) \frac{\partial\left(n_{2}\right)}{\partial x_{h}} \\
\frac{\partial T_{j 2}}{\partial x_{h}} & =-2 n_{1} \frac{\partial}{\partial x_{h}}\left[\operatorname{Re}\left(\frac{\mu_{1} A_{j 1}}{z_{1}}+\frac{\mu_{2} A_{j 2}}{z_{2}}\right)\right]-2 \operatorname{Re}\left(\frac{\mu_{1} A_{j 1}}{z_{1}}+\frac{\mu_{2} A_{j 2}}{z_{2}}\right) \frac{\partial\left(n_{1}\right)}{\partial x_{h}} \\
& +2 n_{2} \frac{\partial}{\partial x_{h}}\left[\operatorname{Re}\left(\frac{A_{j 1}}{z_{1}}+\frac{A_{j 2}}{z_{2}}\right)\right]+2 \operatorname{Re}\left(\frac{A_{j 1}}{z_{1}}+\frac{A_{j 2}}{z_{2}}\right) \frac{\partial\left(n_{2}\right)}{\partial x_{h}}
\end{aligned}
$$

The coefficients $\mu_{\mathrm{j}}$ and $\mathrm{A}_{\mathrm{jk}}$ depend on the material properties and are independent of the boundary nodes coordinates. To calculate the preceding derivatives, the complex values, $\ln \left(\mathrm{z}_{\mathrm{j}}\right)$ and $\left(1 / \mathrm{z}_{\mathrm{j}}\right)$ can be written as

$$
\ln \left(z_{j}\right)=\ln \left|z_{j}\right|+i \arg \left(z_{j}\right) \quad, \quad \frac{1}{z_{j}}=\frac{\bar{z}_{j}}{\left|z_{j}\right|^{2}}
$$

Defining the real functions $\Lambda_{\mathrm{j}}, \Omega_{\mathrm{j}}$ as,

$$
\begin{aligned}
& \Lambda_{1}=\left(x_{1}-\zeta_{1}\right)+\alpha_{1}\left(x_{2}-\zeta_{2}\right) \\
& \Lambda_{2}=\left(x_{1}-\zeta_{1}\right)+\alpha_{2}\left(x_{2}-\zeta_{2}\right) \\
& \Omega_{1}=-\beta_{1} \zeta_{2}+\beta_{1} x_{2} \\
& \Omega_{2}=-\beta_{2} \zeta_{2}+\beta_{2} x_{2}
\end{aligned}
$$

The complex coordinates and their conjugates can be written as

$z_{j}=\Lambda_{j}+i \Omega_{j} \quad, \quad \bar{z}_{j}=\Lambda_{j}-i \Omega_{j}$ 
By substituting equations (26-28) into equations (25), the derivatives of the kernel products with respect to the design variable $\mathrm{x}_{\mathrm{h}}$ can be obtained.

In order to solve a contact problem the boundary constraints are used to relate the unknown tractions and displacements inside the potential contact area. For calculation of the sensitivities of a contact problem the boundary constraints, equations 19 or 23 , must be differentiated with respect to the design variable. The differentiated form of the boundary constraints will create relationships between the derivatives of the displacements and tractions of the node pairs. For the stick node pair $(a, b)$ the differentiated form of equation 19 is,

$$
\frac{d u_{i}^{a}}{d x_{h}}+\frac{d}{d x_{h}}\left(x_{i}^{a}\right)=\frac{d u_{i}^{b}}{d x_{h}}+\frac{d}{d x_{h}}\left(x_{i}^{b}\right), \quad \frac{d t_{i}^{a}}{d x_{h}}+\frac{d t_{i}^{b}}{d x_{h}}=0 . \quad i=1,2
$$

For the frictionless contact the differentiated form of equation 23 is,

$$
\frac{d u_{y}^{b}}{d x_{h}}=\frac{d u_{y}^{a}}{d x_{h}}+\frac{d\left(y^{a}-y^{b}\right)}{d x_{h}}+\frac{d}{d x_{h}}\left[\left(u_{x}^{b}-u_{x}^{a}+x^{b}-x^{a}\right) \tan \theta_{c}\right]
$$

Thus, the design sensitivity analysis is carried out by direct differentiation of the structural response (Eq.18) with respect to design variables.

$$
\frac{\partial A}{\partial x_{h}} U+A \frac{\partial U}{\partial x_{h}}=\frac{\partial B}{\partial x_{h}} \Rightarrow A \frac{\partial U}{\partial x_{h}}=\left(\frac{\partial B}{\partial x_{h}}-\frac{\partial A}{\partial x_{h}} U\right)
$$

This is a set of linear algebraic equations for the unknown gradients, $\frac{\partial U}{\partial x_{h}}$, and equivalent to solving the same equation as equation 18 . Thus, if the quantity in brackets in equation 31 is separately assembled, then the derivatives of displacements and tractions can be computed in one pass by re-entering the equation solver. Following the calculation of displacement gradients, the gradients of stresses can be obtained [2-3]. 
The selection of the boundary point coordinates in the shape optimization process is more flexible than selecting simple geometrical variables such as radii, etc. as the design variables. However, when the entire segments of the boundary or domain are governed by a single variable such as radius, then each shape variable will be associated with the coordinates of a series of boundary nodes. Thus the relevant velocity terms are applied together in the sensitivity analysis with respect to that variable to determine the gradients of the objective function and the constraints.

In the recent study by the author shape design sensitivity analysis of a twodimensional anisotropic domain, which contains a number of voids of arbitrary shapes was carried out [1]. The objective was to perform the design sensitivity analysis of the structure with respect to the translation and rotation of the voids using the boundary element method. The sensitivity analysis, with respect to the design variables such as feature positions and orientations, was achieved by the definition of appropriate design velocity fields for these variables. It was shown that, if the entire boundary is governed by a single geometric variable $(\psi)$ such as radius, the material derivative $\mathrm{F}^{\prime}$ with respect to the variable can be written as

$$
\frac{d F}{d \psi}=\frac{\partial F}{\partial \psi}+\frac{\partial F}{\partial x_{i}} \frac{\partial x_{i}}{\partial \psi}
$$

$\frac{\partial F}{\partial \psi}$ is equal to zero because the shape variables are not explicit terms in the BIE. $\partial \mathrm{F} / \partial \mathrm{x}_{\mathrm{i}}$ are derivatives of the function $\mathrm{F}$ with respect to the coordinates of the nodes located on the boundary. $\partial \mathrm{x}_{\mathrm{i}} / \partial \psi$ can be obtained by the definition of appropriate relations between the boundary point coordinates and the geometric variable $(\psi)$. The function F can be the elastic compliance of the structure, contact stress, displacement, 
etc. The derivatives of the stresses and displacements can be obtained using the relations which were presented earlier in this section.

The elastic compliance is evaluated as the strain energy of the structure

$$
E_{s}=\frac{1}{2} \int_{s} t_{j} u_{j} d s
$$

The derivatives of the elastic compliance, with respect to the boundary point coordinate, $\mathrm{x}_{\mathrm{h}}$, can also be calculated analytically as follows:

$$
\frac{\partial E_{s}}{\partial x_{h}}=\frac{1}{2}\left[\int_{s} \frac{\partial t_{j}}{\partial x_{h}} u_{j} d s+\int_{s} t_{j} \frac{\partial u_{j}}{\partial x_{h}} d s+\int_{s} u_{j} t_{j} \frac{\partial}{\partial x_{h}}(d s)\right]
$$

Equation 34 shows that during the analysis the compliance derivatives are calculated after, the tractions, displacements and their derivatives are obtained.

\section{Results and discussuion}

Three examples are analysed and the results are presented. The accuracy of the sensitivity analysis of the proposed method is verified by the analyses of a cylindrical

roller on an elastic foundation (Fig.2) and the contact of two cylindrical rollers (Fig.3). The third example is related to an inclusion in a composite flat plate subject to uni-axial loading (Fig.4).

Based on the analytical solution for the Hertzian contact of two anisotropic bodies, the pressure distribution, $\mathrm{P}(\mathrm{x})$, in the contact area can be obtained using the following equation [20-22], 


$$
P(x)=-\frac{2 Y}{\pi a}\left(1-\frac{x^{2}}{a^{2}}\right)^{1 / 2}
$$

where $\mathrm{a}$ is the half length of the contact area, $\mathrm{Y}$ is the total force applied and $\mathrm{x}$ is the distance from the centre of the contact. If $\mathrm{P}_{0}$ is the maximum contact pressure then

$$
P_{0}=\frac{2 Y}{\pi a}
$$

If $\mathrm{R}_{\mathrm{A}}$ and $\mathrm{R}_{\mathrm{B}}$ are the radii of the curvature of the two bodies in contact then

$$
a=\sqrt{\frac{2 Y R_{A} R_{B}\left(S_{A}+S_{B}\right)}{\pi\left(R_{A}+R_{B}\right)}}
$$

where $S_{A}$ and $S_{B}$ are found from the following equation for the two elastic materials, respectively.

$$
S_{A} \text { or } S_{B}=-\operatorname{Re}\left\{\frac{a_{22}}{2 i}\left[\frac{1}{\mu_{1}}-\frac{1}{\bar{\mu}_{1}}+\frac{1}{\mu_{2}}-\frac{1}{\bar{\mu}_{2}}\right]\right\}_{A, B}
$$

$\mathrm{a}_{22}, \mu_{1}$ and $\mu_{2}$ are found from equations 2 and 9 , respectively. For an isotropic material $\mu_{1}=\mu_{2}=i$, therefore, $S=2 / E$ for the plane stress state and $S=2\left(1-v^{2}\right) / E$ for the plane strain case.

Combining equations 35-37, the normal stress distribution along the contact area can be obtained from the following equation

$$
P(x)=\sqrt{\frac{Y E^{*}}{\pi R^{*}}-\left(\frac{x E^{*}}{2 R^{*}}\right)^{2}}
$$

where

$$
\begin{gathered}
\frac{1}{R^{*}}=\frac{1}{R_{A}}+\frac{1}{R_{B}} \\
\frac{1}{E^{*}}=\frac{S_{A}+S_{B}}{2}
\end{gathered}
$$


For two isotropic materials in contact with the plane strain condition equation 41 can be written as

$\frac{1}{E^{*}}=\frac{1-v_{A}^{2}}{E_{1}}+\frac{1-v_{B}^{2}}{E_{2}}$

where $v_{\mathrm{A}}$ and $v_{\mathrm{B}}$ are the Poisson's ratios of the bodies in contact. $\mathrm{R}^{*}$ and $\mathrm{E}^{*}$ are usually called the equivalent moduli of elasticity and equivalent radius, respectively. Here, $\mathrm{E}^{*}$ is called the equivalent material stiffness for the anisotropic materials in contact.

Fig. 2 shows the geometry of a cylinder on an elastic foundation where $W=H=3 R$ and $\mathrm{R}=50$ and frictionless contact is assumed. Four different materials are considered for the elastic foundation; steel, aluminium, graphite-epoxy and Kevlar-epoxy, respectively. The cylinder is made of steel. The properties of the selected materials are shown in Table 1. Every component is being treated as a lamina that has four engineering constants, $\mathrm{E}_{\mathrm{L}}, \mathrm{E}_{\mathrm{T}}, \mathrm{G}_{\mathrm{LT}}$ and $\mathrm{v}_{\mathrm{LT}}$ with a lamina orientation angle of zero. Steel and Aluminium are isotropic materials but in the current analysis it is assumed as if they are anisotropic $\left[E_{L}=E_{T}, G_{L T}=0.5 \times E_{L}\left(1+v_{L T}\right)\right]$. It is also assumed that for each anisotropic material the fibre direction $(\mathrm{L})$ is in the same direction as the applied $\operatorname{load}(\mathrm{Y})$.

Fig. 5 illustrates the contact pressure distributions obtained numerically using the BEM and analytically using equation 39 , which are in very good agreement. The same contact area is assumed for the selected materials with the contact half-length of $\mathrm{a}=0.082 \mathrm{R}$. The stresses are normalized with respect to the maximum pressure at the centre of the contact when the steel cylinder is in contact with the steel foundation 
$P_{s}=\left(P_{0}\right)_{\text {Steel } / \text { Steel }}$. The results clearly show that as the foundation becomes less rigid $\left(\mathrm{S}_{\mathrm{B}}<\mathrm{S}_{\mathrm{A}}\right)$ the normal contact stress shows a marked decrease and therefore, the load needed to obtain the same contact zone area decreases. For example, the load required for the contact bodies of Steel/Kevlar is almost $20 \%$ of the contact bodies Steel/Steel.

Next, the sensitivities of the contact pressure with respect to the radius of the cylinder are calculated using BEM and compared with the corresponding values obtained analytically. The radius of the cylinder is taken as the only shape variable. As explained in section 4, the shape variable is associated with the coordinates of a series of boundary nodes, related to the boundary element discretization of the structure. If $(\psi)$ in equation 32 is the radius of the domain then coordinates of each boundary point on this domain is $x_{i}=\psi n_{i}$, where $\mathrm{n}_{\mathrm{i}}$ is the fixed direction cosine at the boundary. Therefore, for each boundary point $x_{i}^{\prime}=\partial x_{i} / \partial \psi=n_{i}$. Fig. 6 shows the sensitivities of the contact pressure with respect to $\mathrm{R}^{*}$ obtained using the BEM.

In order to obtain the corresponding analytical values, the Hertzian equation (39) is differentiated with respect to the radius of the cylinder $\left(\mathrm{R}^{*}=\mathrm{R}_{\mathrm{A}}\right)$, where $\mathrm{R}_{\mathrm{B}}$ is infinite.

$$
\frac{\partial P(x)}{\partial R^{*}}=\frac{Y E^{*}}{2 \pi R^{* 2} P(x)}-\frac{P(x)}{R^{*}}
$$

Fig. 6 shows the derivatives of the contact pressure with respect to the radius for the contact material systems studied in Fig. 5. The sensitivities are normalized with respect to the sensitivity of the maximum contact pressure (at $x=0$.) for the case when the steel cylinder is in contact with the steel foundation. The numerical and analytical results are in good agreement. Fig. 6 also shows that irrespective of the material 
properties at about $\mathrm{x}=0.7 \mathrm{a}$, the derivative of the contact pressure with respect to the radius is zero. This can also be proved analytically. Combining equations 37, 39 and 43, when $\frac{\partial P(x)}{\partial R^{*}}=0$. shows that at the point where the derivative of the contact pressure is zero $\left(x=a_{0}\right)$, the following relation is satisfied.

$a_{0}=\frac{a}{\sqrt{2}}$

In a recent study by Sfantos and Aliabadi [13], a boundary element sensitivity formulation for contact problems using the implicit differentiation method was presented. They differentiated the boundary integral equation analytically with respect to the shape design variables such as radii. In their formulation the design variables were defined in terms of the normal gap between the contact bodies where the derivative of the normal gap with respect to the design variables was calculated using the finite difference scheme. They also analysed the above example where both the cylinder and foundation had identical isotropic material properties. Their results agreed very well with the corresponding analytical results.

The next example is the Hertzian contact of two cylindrical rollers subject to the compressive force Y. See Fig. 3. The rollers are made of graphite-epoxy and steel, respectively, with the properties shown in Table 1. It is assumed that for the graphiteepoxy cylinder the fibre direction (L) is in the same direction as the applied load (Y). Three different loading cases are considered which obviously will result to three different contact zone sizes, with the contact half-length of $a=0.105 \mathrm{R}^{*}, 0.157 \mathrm{R}^{*}$ and 0.21R*, respectively. Fig. 7 shows the contact pressure distribution along the contact area obtained using BEM and also the corresponding analytical results calculated using equation 39, which are in very good agreement. Fig. 8 shows the gradients of 
the contact pressure with respect to the equivalent radius $\mathrm{R}^{*}$ calculated analytically using equation 43 and numerically using BEM which are again in very good agreement. In Figs 7 and 8 the contact pressure and its derivative are normalized with respect to the equivalent material stiffness $E^{*}$ of the contact material system steel/graphite-epoxy (Eq. 41). The results show that for each loading case when $\mathrm{x}<\mathrm{a}_{0}$ the sensitivities are negative and almost have a steady variation with respect to $\mathrm{x}$. For $\mathrm{x}>\mathrm{a}_{0}$ the sensitivities are positive and will increase exponentially. It should be noted that at $\mathrm{x}=\mathrm{a}_{0}$ the gradient is zero where $\mathrm{a}_{0}=0.7 \mathrm{a}$.

The next example is related to the contact of a circular inclusion in a square plate. The objective is to find the stress distribution in the contact region and the sensitivities of the overall strain energy with respect to the radial positions of a series of points around the boundary of the hole. Fig. 4 shows a square plate with a central circular inclusion subject to uni-axial loading in the $\mathrm{x}$ direction. The insert and the hole in the plate have the same diameter when unloaded. This is a receding type of contact where the contact region reduces as the load is applied. Each edge of the square plate is $16 \mathrm{~m}$ and the diameter of the inclusion is $2 \mathrm{~m}$. Different combinations of the materials are selected for the plate and the inclusion. For the properties of the materials refer to Table 1. For the composite materials the fibre direction is in the same direction as $\mathrm{x}$ axis.

The analytical solution for an isotropic infinite plate with a circular inclusion of the same material is given by Stippes et al [23] for the frictionless case. They calculated the radial and circumferential stresses on the boundaries of the inclusion and the plate. They concluded that the angle of contact is independent of the elastic properties. 
Wilson [24] applied the same analytical approach for the case when the isotropic plate and the inclusion are made of different isotropic materials.

Fig. 9 shows the circumferential and radial stresses calculated numerically using BEM for an aluminium plate with an aluminium inclusion. Fig.9 also shows the corresponding stresses of an aluminium plate with the steel and graphite-epoxy inclusions. As expected, the steel inclusion with the higher stiffness will create higher contact stress and slightly lower contact angle. However, the graphite-epoxy inclusion will produce lower radial stresses but higher circumferential stresses.

Fig. 10 shows a similar set of results for a graphite-epoxy plate with an aluminium, steel or graphite-epoxy inclusion. The dimensions and loading are shown in Fig. 4. For the sake of comparison, the circumferential stresses around the hole in the plate, in the absence of the inclusion, are also included in Fig. 10. It can be seen that the circumferential stresses around the hole in the graphite-epoxy plate, with the high $\mathrm{E}_{\mathrm{L}} / \mathrm{E}_{\mathrm{T}}$ ratio, are relatively higher than the corresponding stresses in the aluminium plate studied earlier. The maximum radial stress in the graphite-epoxy plate with the steel inclusion is about $75 \%$ higher than the corresponding value of the graphiteepoxy plate with the graphite-epoxy inclusion, as expected. General-speaking, the inclusions will lower the circumferential stresses around the hole but the amount of reduction by the steel or aluminium inclusion is much higher than the amount of reduction by the graphite-epoxy inclusion.

In a recent study of the author, the optimal design of an anisotropic elastic body of maximum stiffness and minimum weight under specified loadings and using the 
boundary element method, was obtained. The design variables were the coordinates of some points on the movable part of the boundary where shape is to be optimized. The Hermitian cubic spline functions which are combinations of piecewise cubic curves, with continuous first and second derivatives at the ends of each curve, were used to represent the boundary shape. This provides a flexible and compact method for defining boundary geometry using a small number of design variables. The elastic compliance or the total strain energy of the structure was minimized while there were constraints on the maximum stress and weight of the structure. During the optimization process the derivatives of the overall strain energy of the structure with respect to the design variables were required. Similarly, in order to obtain the optimum shapes of two bodies in contact with the maximum stiffness, the sensitivities of the elastic compliance with respect to the design variables must be evaluated, equation 43.

Next, the gradients of the overall strain energy of the plate with inclusion are obtained. The radii of a series of points around the boundary of the hole at the fixed angles are selected as the design variables. First, the derivatives of the overall strain energy are taken with respect to the Cartesian coordinates of the design variable points, then using the following equation the sensitivities are calculated with respect to the radii of these points.

$$
\frac{\partial E}{\partial R_{i}}=\frac{\partial E}{\partial x_{i}} \sin \left(\theta_{i}\right)+\frac{\partial E}{\partial y_{i}} \cos \left(\theta_{i}\right)
$$

The design variables are either in the contact or non-contact zone. Fig.11 shows the sensitivities of the overall strain energy of the plates with inclusion (Figs. 9 and 10) with respect to the radii of the points around edge $\mathrm{AB}$ (Fig.4). The results show that the trend in variation of the sensitivities is mainly influenced by the material property 
of the inclusion. In the case of the plate with the aluminium or steel inclusion, the sensitivities have a uniform variation inside the contact zone and a highly nonlinear variation outside the contact region. The gradients of the plate with the graphiteepoxy inclusion have nonlinear variation both inside and outside the contact zone. Irrespective of the material properties, for $\theta>60^{\circ}$, the sensitivity of the compliance with respect to the radial position of the boundary point is relatively small.

The sensitivities of the plate with the steel or aluminium inclusion are relatively lower than the corresponding values in the plate with the graphite-epoxy inclusion. However, it should be noted that the sensitivities must be normalized before being used in a shape optimization algorithm because the normalization provides a simple means of identifying the important parameters in the design [2,5]. The simplest approach is to find the maximum absolute gradient component, then normalize all the sensitivities by dividing them to this scaling factor.

At present the variable points are selected on the boundary of the plate's hole. However, during the iterative procedure of the shape optimization appropriate constraints must be applied to reach a feasible design for the contact surface, for the maximum stiffness while minimizing the maximum contact pressure of the structure.

\section{Summary and conclusion}

Following a brief review of the mathematical basis of the BIE method for two elastic anisotropic materials in contact, analytical differentiation of the BIE was carried out with respect to the positions of the boundary nodes. Shape design sensitivity analysis was performed to compute the derivatives of displacements, stresses, elastic 
compliance, etc with respect to changes of boundary point coordinates. In the case when entire segments of the boundary or domain are governed by a single variable such as radius, then each shape variable was associated with the coordinates of a series of boundary nodes, Thus the relevant velocity terms are applied together in the sensitivity analysis with respect to that variable to determine the gradients with respect to the design variables. Due to the general approach and flexibility in the selection of the design variables the proposed formulation can be employed in conjunction with the optimization algorithms for the shape optimization of anisotropic components with arbitrary shapes in contact.

The sensitivity analysis algorithm was validated using the test cases with known analytical solutions. Three example problems have been analysed and the results are presented. Four different anisotropic materials were employed for the analysis. The isotropic materials were treated as if they were anisotropic. The results showed the influence of the material properties in the sensitivities of the anisotropic components in contact. 


\section{REFERENCES}

1. Tafreshi A., "Shape design sensitivity analysis with respect to the positioning of features in composite structures using the boundary element method", Engineering Analysis with boundary elements, 2006; 30:1-13

2. Tafreshi A., "Optimum shape design of composite structures using the boundary element method" AIAA J, 2005; 43(6):1349-59

3. Tafreshi A., "Shape design sensitivity analysis of 2D anisotropic structures using the boundary element method", Engineering analysis with Boundary elements, 2002; 26: 237-251

4. Tafreshi A. Fenner R.T., "Design optimization using the boundary element method”, J Strain Anal, 1991;26(4): 231-241

5. Tafreshi A., "Design optimization using the boundary element method", $\mathrm{PhD}$ Dissertation, Imperial College of Science, Technology and Medicine, University of London, 1990

6. Johnson K L, "Contact mechanics”, Cambridge University Press, 2001

7. Karami, G, "A boundary element method for two-dimensional elastic contact problems", Heidelberg: Springer 1989

8. Paris, F. and Garrido, J.A., "On the use of discontinuous elements in 2D contact problems, Proceedings of boundary elements VII, vol.13. Southampton: Computational Mechanics Publications; 1985: 27-39

9. Simunvic S. Saigal S, "Contact surface optimization using boundary element method", Computers and structures, 1995; 56(5): 745-750

10. Alessandri C., Tralli, A., "Sensitivity analysis for unilateral contact problems: Boundary variational formulations and BEM discretizations, Computational Mechanics, 1995; 15: 287-300 
11. Stupkiewicz S., Korelc J, Dutko M, Rodic T, "Shape sensitivity analysis of large deformation frictional contact problems", Comput. Methods Appl. Mechs. Engng, 2002; 191: 3555-3581

12. Paczelt I Mroz Z.,'Optimal shapes of contact interfaces due to sliding wear in the steady relative motion", Int J Solids and Structuers, 2007; 44: 895-925

13. Sfantos G.K., Aliabadi, M.H., "A boundary element sensitivity formulation for contact problems using the implicit differentiation method", Engineering analysis with boundary elements, 2006; 30: 22-30

14. Gibson R F, "Principles of composite material mechanics", New-York, McGraw-Hill; 1994

15. Lekhnitskii S.G.,"Theory of elasticity of an anisotropic elastic body", San Fransisco: Holden-Day, 1963

16. Synder M.D. and Cruse T.A., "Boundary integral equation analysis of cracked anisotropic plates", Int. J. Fract. 1975; 11(2): 315-28

17. Cruse T A, "Boundary element analysis in computational fracture mechanics" Dordrecht: Kluwer, Academic Publishers; 1988

18. Tan C.L., Gao, Y.I. and Afagh F.F, “Anisotropic stress analysis of inclusion problems using the boundary integral equation method", Journal of Strain Analysis, 1992; 27(2): 67-76

19. Segond, D. and Tafreshi A., "Stress analysis of three-dimensional contact problems using the boundary element method", Engineering Analysis with boundary elements, 1998; 22: 199-214

20. Willis J R, "Hertzian contact of anisotropic bodies", J Mech. and Phys. Of Solids, 1966; 14(3): 163-176 
21. Sveklo, V.A.,"The action of a stamp on an elastic anisotropic half-space", Prik Mat Mekh, 1970; 34(1)

22. Chen W.T., "Stresses in some anisotropic materials due to indentation and sliding”, Int. J. Solids and Structures, 1969; 5:191-214

23. Stippes M., Wilson H.B. and Krull F.N., "A contact stress problem for a smooth disk in an infinite plate", In Proceedings of the fourth United States National Congress Applied Mechanics, 1962: 799-806

24. Wilson H. B., "Approximate determination of contact stresses in an infinite plate with a smooth circular insert", In: Proceedings of the second south eastern conference on Theoretical and Applied Mechanics, 1964, 147-63 
Table 1 Elastic properties of the selected materials

\begin{tabular}{|l|l|l|l|l|l|l|l|}
\hline Material & Elastic & $\mathrm{E}_{\mathrm{L}}$ & $\mathrm{E}_{\mathrm{T}}$ & $v_{\mathrm{LT}}$ & $\mathrm{G}_{\mathrm{LT}}$ & \multicolumn{2}{|l|}{ Complex parameters } \\
no. & properties & $\mathrm{GPa}$ & $\mathrm{GPa}$ & $\mathrm{GPa}$ & $\mathrm{GPa}$ & $\mu_{1}$ & \multicolumn{2}{|c|}{$\mu_{2}$} \\
\hline 1 & Steel & 210.9 & 210.9 & 0.29 & 81.744 & $\mathrm{i}$ & $\mathrm{i}$ \\
\hline 2 & Aluminium & 70.0 & 70.0 & 0.3 & 26.923 & $\mathrm{i}$ & $\mathrm{i}$ \\
\hline 3 & Graphite-epoxy & 135.0 & 8.69 & 0.25 & 7.52 & $4.063 \mathrm{i}$ & $0.969 \mathrm{i}$ \\
\hline 4 & Kevlar-epoxy & 85.5 & 5.5 & 0.35 & 3.08 & $5.145 \mathrm{i}$ & $0.766 \mathrm{i}$ \\
\hline
\end{tabular}

L: Longitudinal T:Transverse 


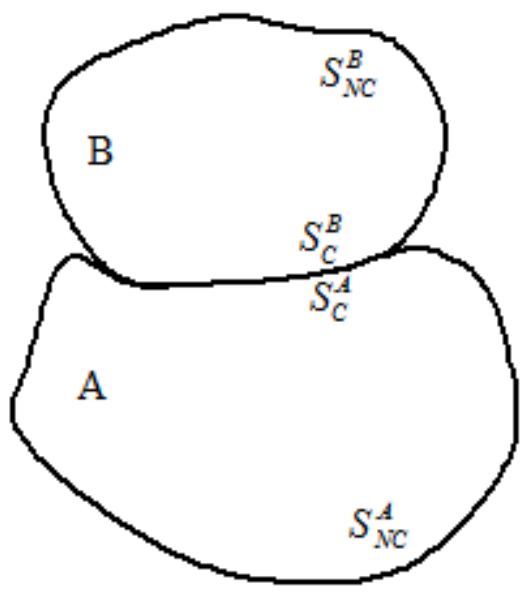

Fig. 1 Contact between two bodies

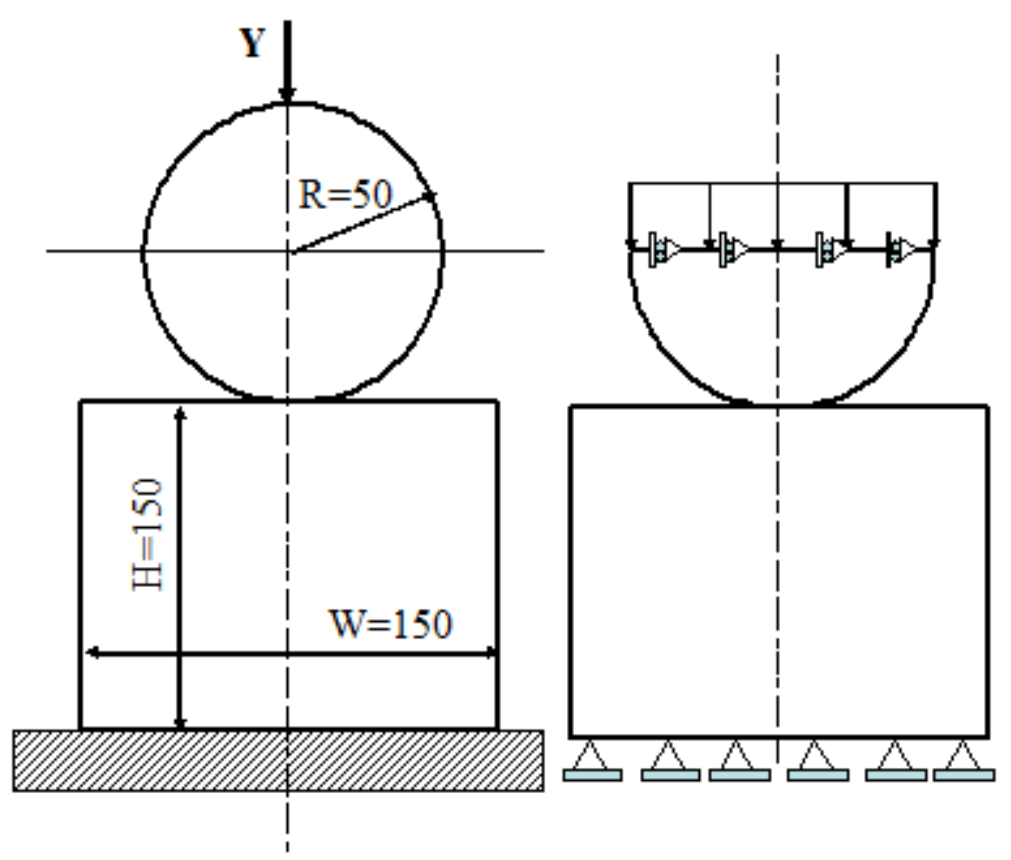

Figure 2 Contact of a cylinder on a flat foundation 


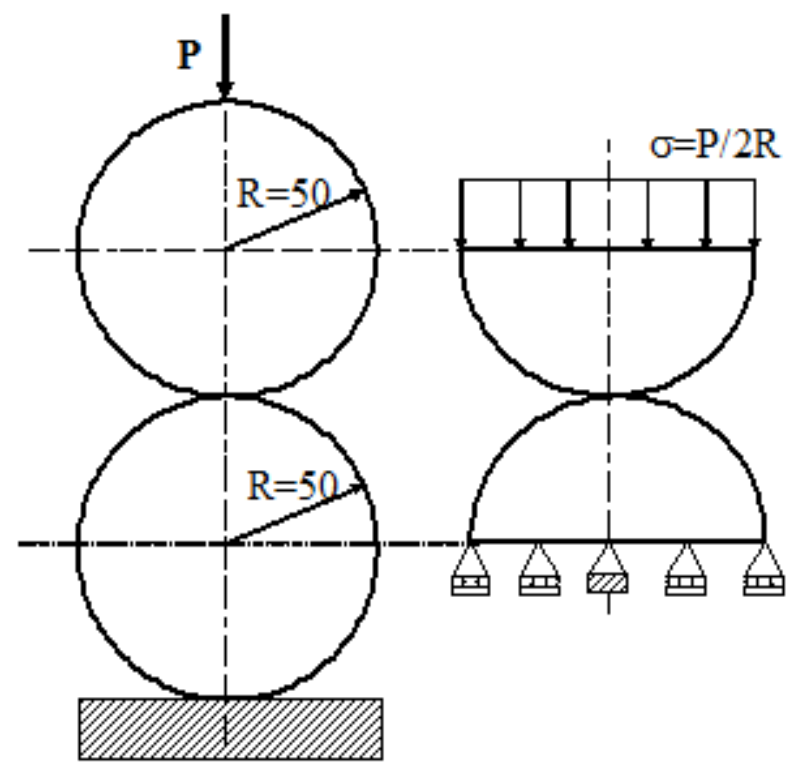

Figure 3 Contact of tw o identical cylindrical rollers

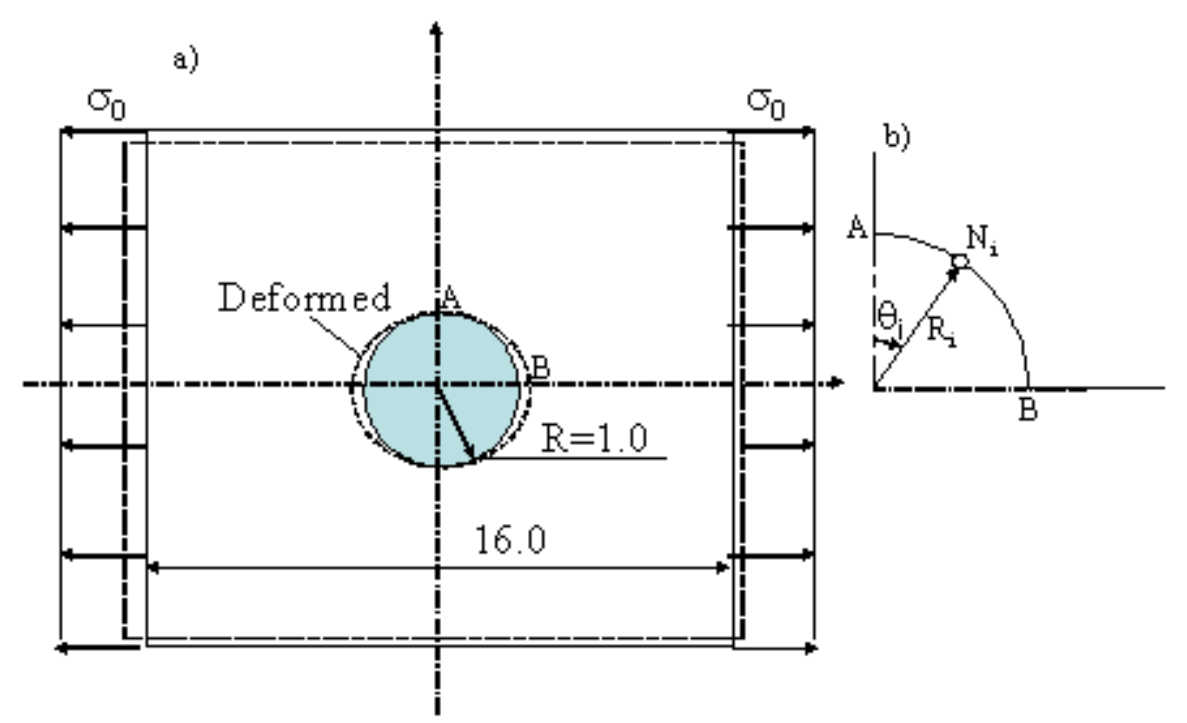

Figure 4 a)A plate with a centr al circular inclusion subject to uniaxial lo ading b)Position of a design variable point on the edge $\mathrm{AB}$ 


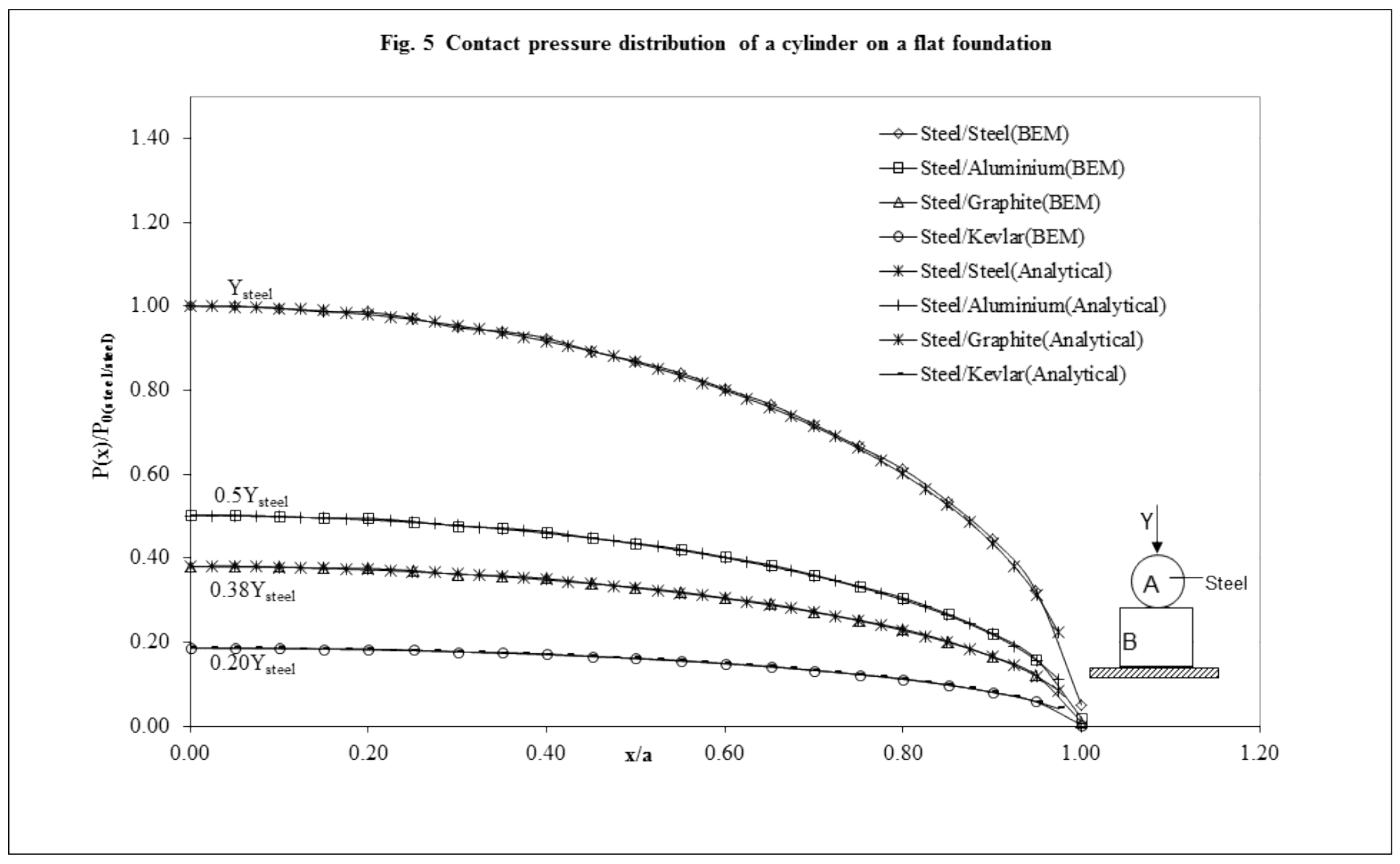




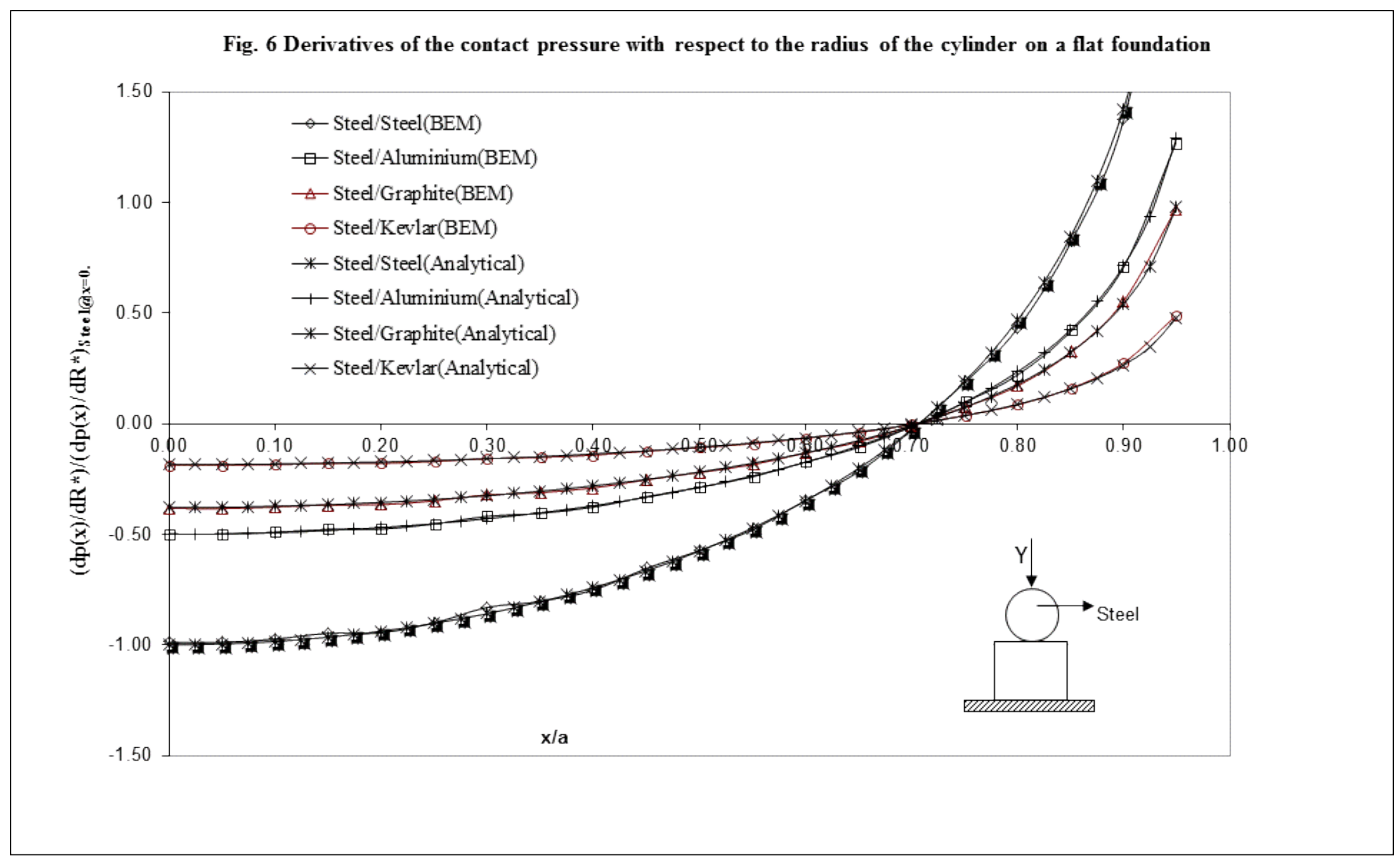




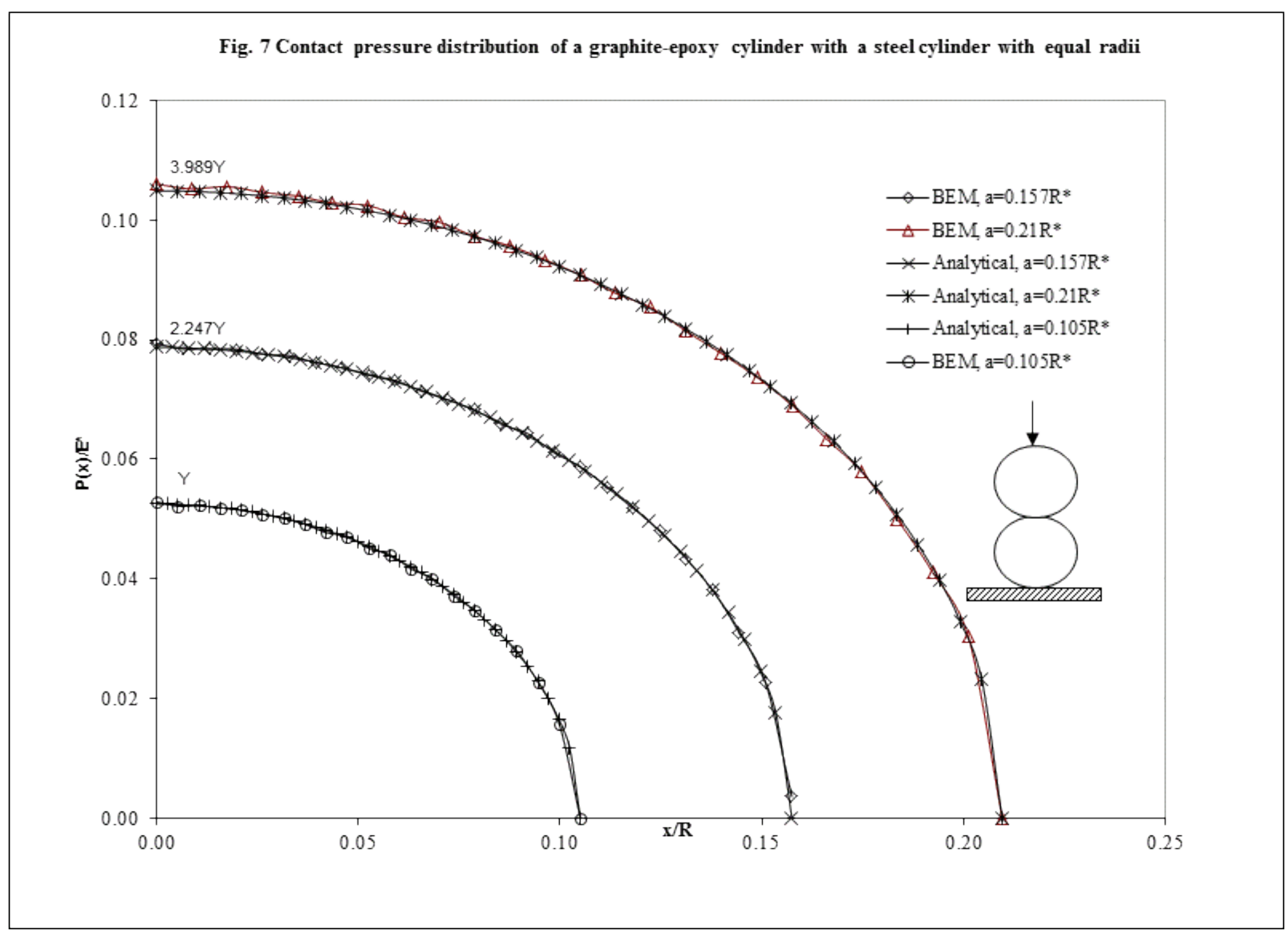




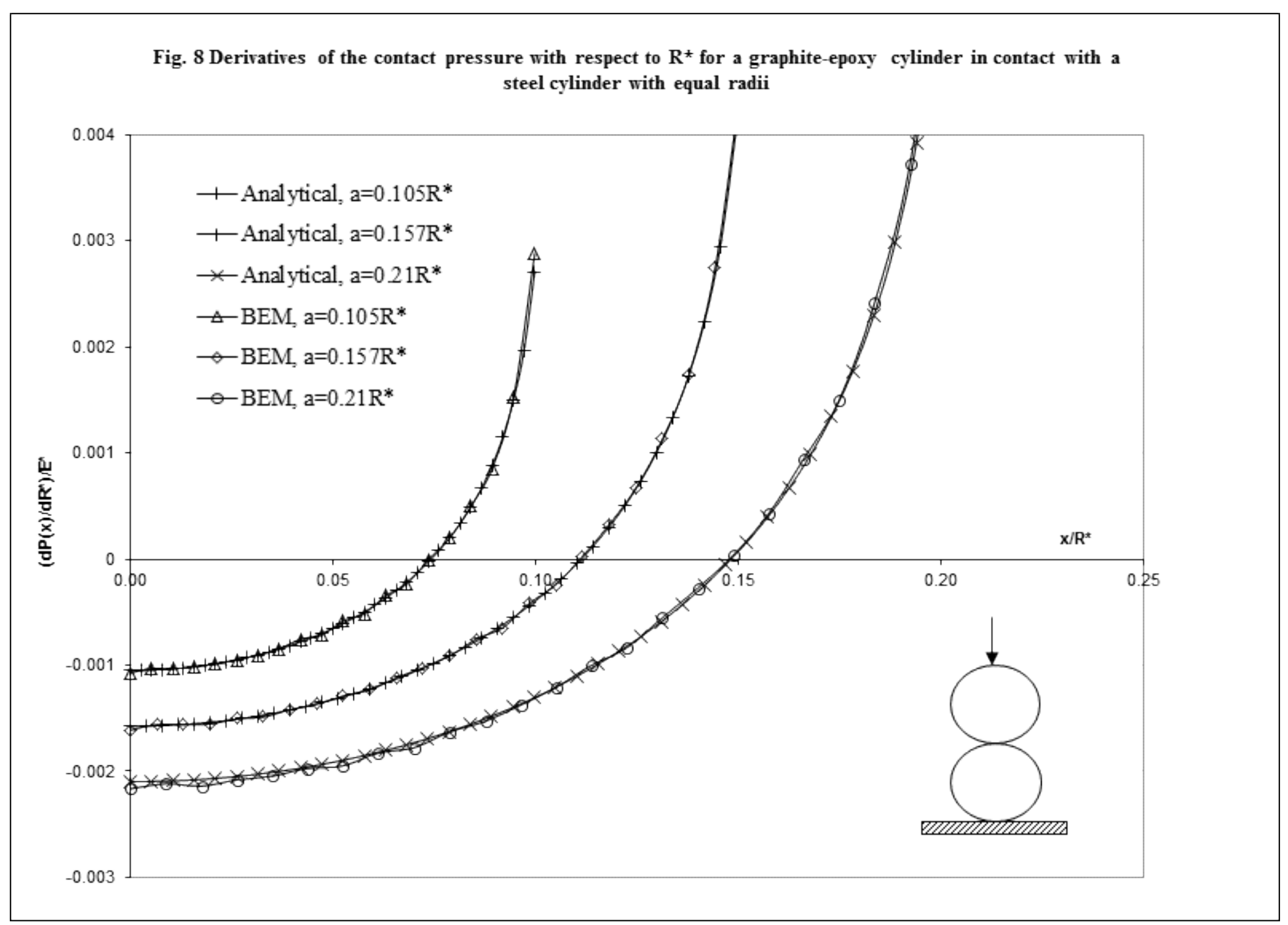




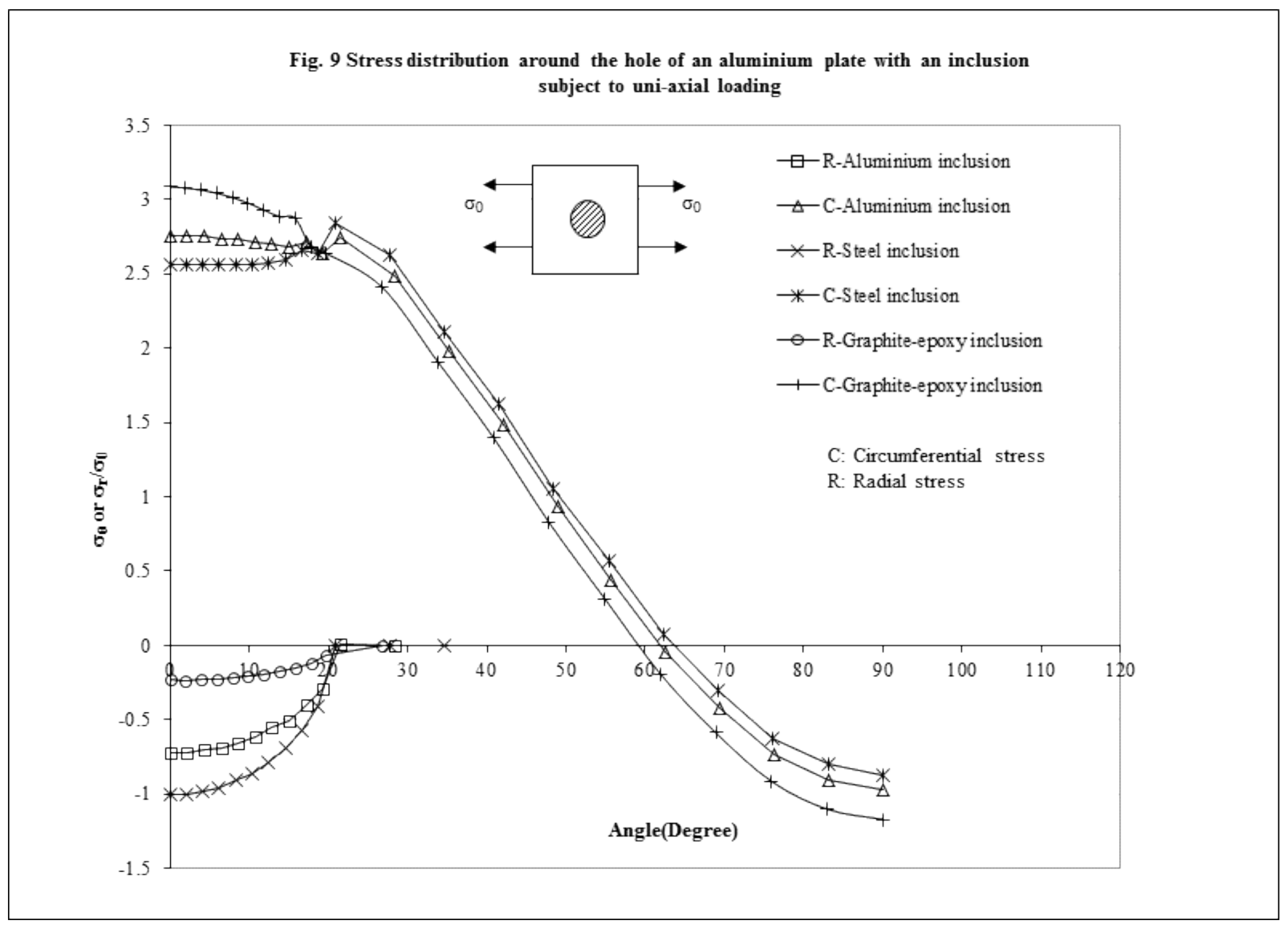




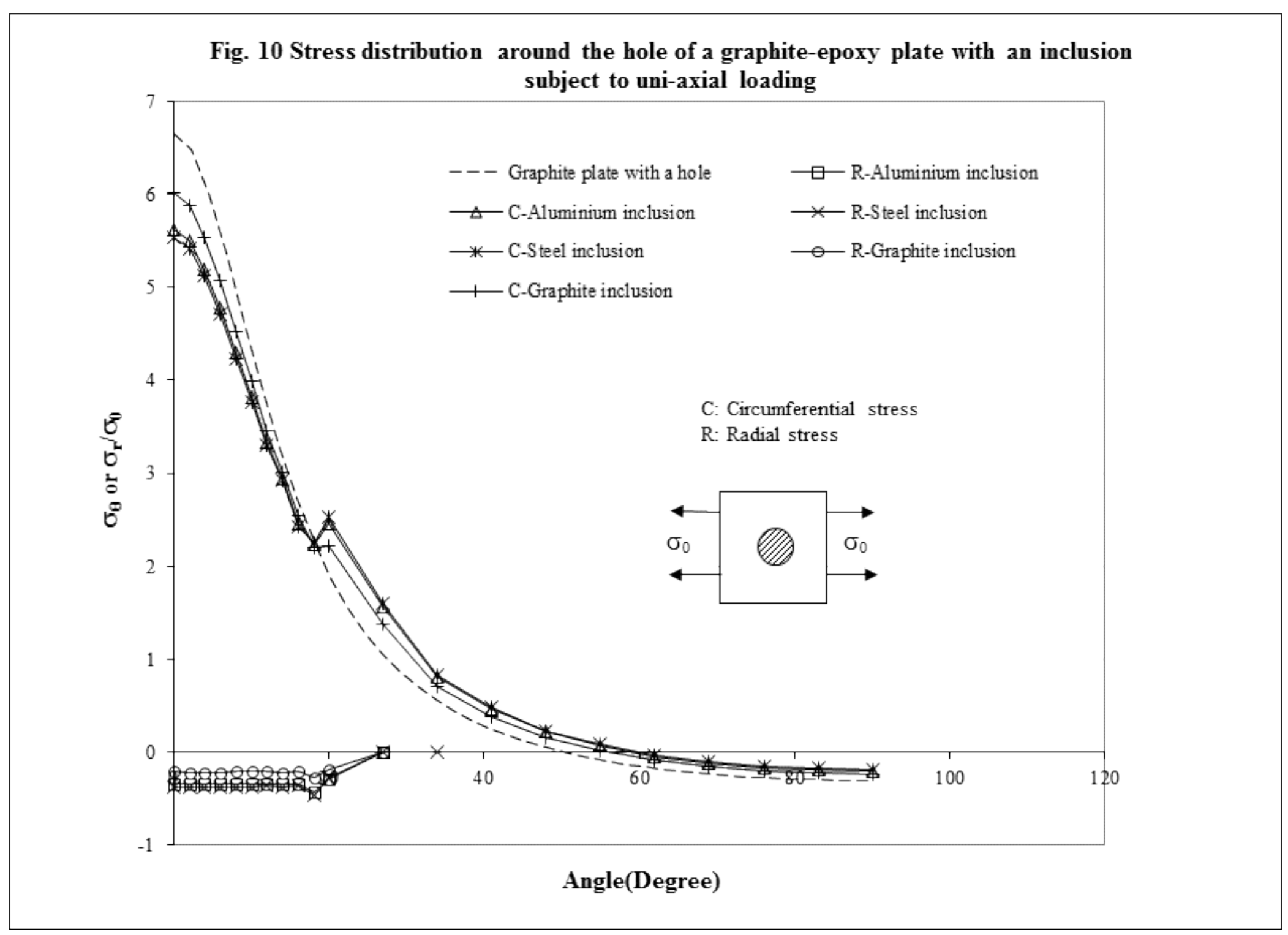




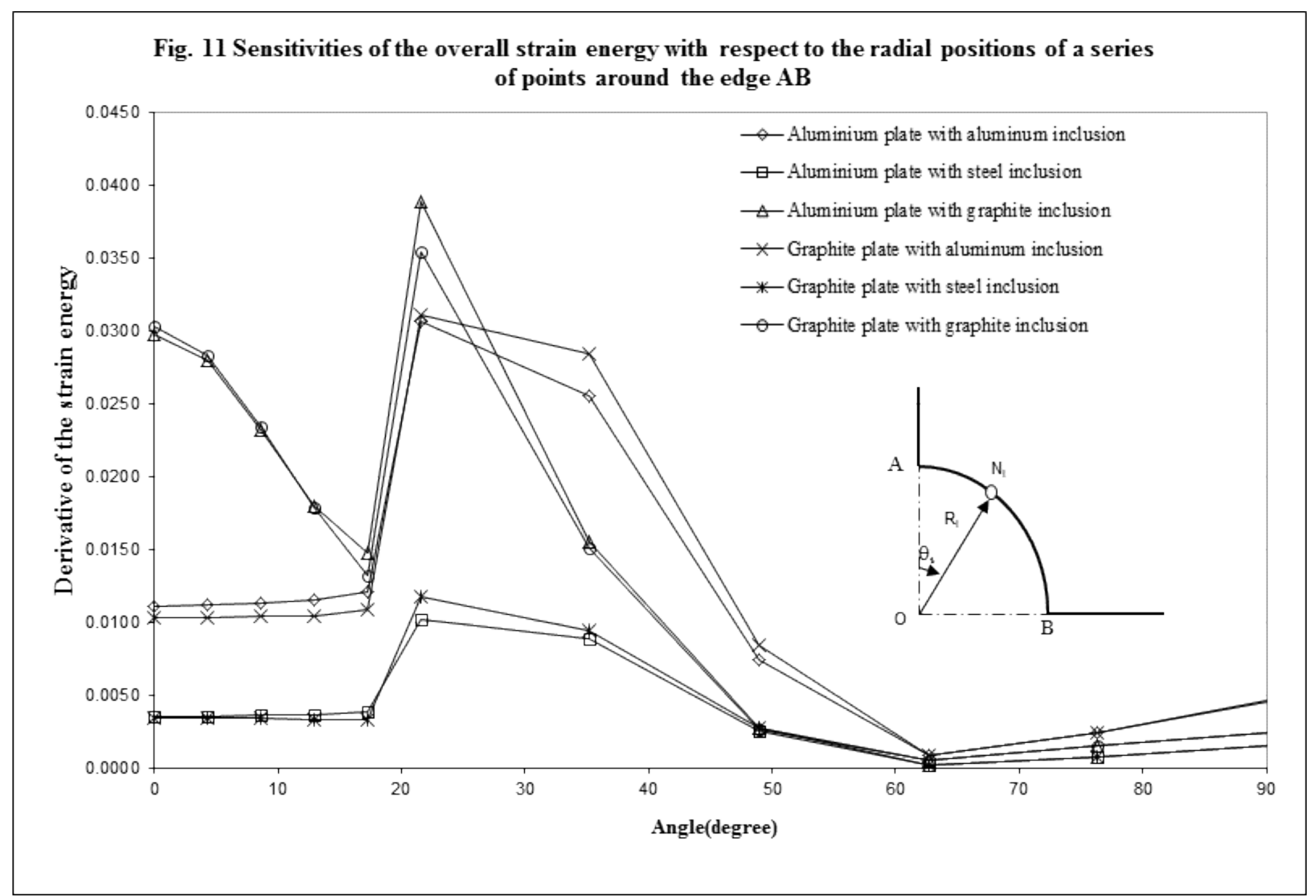

